\title{
Aerobic Glycolysis in the Frontal Cortex Correlates with Memory Performance in Wild-Type Mice But Not the APP/ PS1 Mouse Model of Cerebral Amyloidosis
}

\author{
Richard A. Harris, ${ }^{1}$ Lauren Tindale, ${ }^{1}$ Asad Lone, ${ }^{1}$ Olivia Singh, ${ }^{1}$ Shannon L. Macauley, ${ }^{2}$ Molly Stanley, ${ }^{2}$ \\ David M. Holtzman, ${ }^{2}$ Robert Bartha, ${ }^{3}$ and Robert C. Cumming ${ }^{1}$ \\ ${ }^{1}$ Department of Biology, University of Western Ontario, London, Ontario N6A 5B7, Canada, ${ }^{2}$ Department of Neurology, Hope Center for Neurological \\ Disorders, Knight Alzheimer's Disease Research Center, Washington University School of Medicine, St. Louis, Missouri 63110, and ${ }^{3}$ Department of \\ Physiology and Pharmacology, University of Western Ontario, and Molecular Brain Research Group, Robarts Research Institute, London, Ontario N6A 5B7, \\ Canada
}

Aerobic glycolysis and lactate production in the brain plays a key role in memory, yet the role of this metabolism in the cognitive decline associated with Alzheimer's disease (AD) remains poorly understood. Here we examined the relationship between cerebral lactate levels and memory performance in an APP/PS1 mouse model of $\mathrm{AD}$, which progressively accumulates amyloid- $\beta$. In vivo ${ }^{1} \mathrm{H}$-magnetic resonance spectroscopy revealed an age-dependent decline in lactate levels within the frontal cortex of control mice, whereas lactate levels remained unaltered in APP/PS1 mice from 3 to 12 months of age. Analysis of hippocampal interstitial fluid by in vivo microdialysis revealed a significant elevation in lactate levels in APP/PS1 mice relative to control mice at 12 months of age. An age-dependent decline in the levels of key aerobic glycolysis enzymes and a concomitant increase in lactate transporter expression was detected in control mice. Increased expression of lactate-producing enzymes correlated with improved memory in control mice. Interestingly, in APP/PS1 mice the opposite effect was detected. In these mice, increased expression of lactate producing enzymes correlated with poorer memory performance. Immunofluorescent staining revealed localization of the aerobic glycolysis enzymes pyruvate dehydrogenase kinase and lactate dehydrogenase A within cortical and hippocampal neurons in control mice, as well as within astrocytes surrounding amyloid plaques in APP/PS1 mice. These observations collectively indicate that production of lactate, via aerobic glycolysis, is beneficial for memory function during normal aging. However, elevated lactate levels in APP/PS1 mice indicate perturbed lactate processing, a factor that may contribute to cognitive decline in $\mathrm{AD}$.

Key words: aerobic glycolysis; Alzheimer’s disease; amyloid; lactate; magnetic resonance spectroscopy; memory

\section{Significance Statement}

Lactate has recently emerged as a key metabolite necessary for memory consolidation. Lactate is the end product of aerobic glycolysis, a unique form of metabolism that occurs within certain regions of the brain. Here we detected an age-dependent decline in the expression of aerobic glycolysis enzymes and a concomitant decrease in lactate levels within the frontal cortex of wild-type mice. Improved memory performance in wild-type mice correlated with elevated expression of aerobic glycolysis enzymes. Surprisingly, lactate levels remained elevated with age and increased aerobic glycolysis enzyme expression correlated with poorer memory performance in APP/PS1 mice. These findings suggest that while lactate production is beneficial for memory in the healthy aging brain, it might be detrimental in an Alzheimer's disease context.

\section{Introduction}

Memory consolidation and retrieval are energetically demanding processes. Cerebral activation is quickly followed by a regional

Received Aug. 13, 2015; revised Dec. 8, 2015; accepted Dec. 23, 2015.

Author contributions: R.A.H., S.L.M., M.S., D.M.H., R.B., and R.C.C. designed research; R.A.H., L.T., A.L., O.S., S.L.M., M.S., and R.C.C. performed research; D.M.H. contributed unpublished reagents/analytic tools; R.A.H., S.L.M., M.S., D.M.H., R.B., and R.C.C. analyzed data; R.A.H., S.L.M., and R.C.C. wrote the paper.

This work was supported in part by the Natural Sciences and Engineering Research Council of Canada (3558032013 , to R.C.C.), the Scottish Rite Charitable Foundation (11103, to R.C.C.), the Canada Foundation for Innovation (22167, to R.C.C.), the Canadian Consortium on Neurodegeneration in Aging (137794, to R.C.C. and R.B.), the increase in blood flow, glucose uptake, and glycolytic metabolism (Fox et al., 1988). The astrocyte-neuron lactate shuttle hypothesis posits that astrocytes process glucose by aerobic glycolysis to

National Institutes of Health (F32 NS080320, to S.L.M.; P01 NS080675, to D.M.H.), a New Vision Award through Donors Cure Foundation (to S.L.M.), and the National Science Foundation (DGE-1143954, to M.S.).

The authors declare no competing financial interests.

Correspondence should be addressed to Robert C. Cumming, Department of Biology, University of Western Ontario, 1151 Richmond Street North, London, 0N N6A 5B7, Canada. E-mail: rcummin5@uwo.ca.

DOI:10.1523/JNEUROSCI.3131-15.2016

Copyright $\odot 2016$ the authors $\quad 0270-6474 / 16 / 361871-08 \$ 15.00 / 0$ 
generate lactate as a metabolic intermediate, which is subsequently used as a primary fuel source for neurons (for review, see Magistretti and Allaman, 2015). Aerobic glycolysis can be described as the reliance on glycolysis, even when oxygen is not rate-limiting, with the concomitant production of lactate as a by-product (Lunt and Vander Heiden, 2011). Emerging evidence suggests that lactate production and transport between astrocytes and neurons is required for long-term memory formation (Newman et al., 2011; Suzuki et al., 2011). Lactate has also been identified as a novel signaling molecule in the brain (Mosienko et al., 2015) responsible for induced expression of genes associated with synaptic plasticity (Yang et al., 2014).

Alzheimer's disease (AD) is the most common form of dementia among the elderly and is characterized by the accumulation of cerebral plaques primarily composed of amyloid- $\beta$ peptide $(A \beta)$. Although aberrant $A \beta$ processing and accumulation has strongly been associated with $\mathrm{AD}$, the exact cause of dementia in $\mathrm{AD}$ patients is still poorly defined. Recent studies revealed that a reduction in cerebral metabolism precedes neurodegeneration, is closely linked with amyloid pathology, and correlates with cognitive decline in AD (Mosconi et al., 2006). In addition to cell loss, cerebral hypometabolism in the $\mathrm{AD}$ brain may arise, in part, by $\mathrm{A} \beta$ deposition, which is known to disturb mitochondrial function, leading to impaired energy metabolism (Atamna and Frey, 2007). A recent positron emission tomography (PET) imaging study revealed a strong correlation between the spatial distribution of aerobic glycolysis and $\mathrm{A} \beta$ deposition in the human brain (Vlassenko et al., 2010). Thus aerobic glycolysis may represent an adaptive mechanism that permits sufficient energy production regardless of $\mathrm{A} \beta$-mediated impairment of mitochondrial respiration. However, it is currently unknown whether aerobic glycolysis and the associated production of lactate is either beneficial or detrimental in an $\mathrm{AD}$ context.

Here we examined CNS metabolism within an APP/PS1 mouse model of AD to test the hypothesis that lactate production in the brain plays a key role in memory formation and is altered by amyloid deposition with age. Our findings suggest that lactate production in the frontal cortex declines naturally with age and expression of enzymes that contribute to its production correlates highly with improved memory performance in control mice, but not in APP/PS1 mice.

\section{Materials and Methods}

Animals. Male APPswe/PSEN1dE9 mice (Jankowsky et al., 2001) were maintained on a C57BL/6J background (Charles River Laboratories International), henceforth referred to as APP/PS1 mice. All animals were housed under a $12 \mathrm{~h}$ light/dark cycle with ad libitum access to breeder chow base diet (Mouse Diet 5015, LabDiet) in compliance with the Canadian Council of Animal Care guidelines. Spatial memory was assessed as previously described (Morris, 1984) using the Morris water maze (MWM).

${ }^{1} \mathrm{H}$ magnetic resonance spectroscopy. Mice were anesthetized with $2 \%$ isoflurane and scanned using a 9.4 T small-animal MRI scanner equipped with a $30 \mathrm{~mm}$ millipede volume radiofrequency coil (Agilent). T2-weighted images were acquired and a voxel $\left(2 \times 4 \times 3 \mathrm{~mm}^{3}\right)$ was localized to the frontal cortex for magnetic resonance spectroscopy (MRS) using a LASER (localization by adiabatic selective refocusing) pulse sequence with the following parameters: TR/TE = $4000 / 270 \mathrm{~ms}, 384$ averages for the metabolite spectrum with water suppressed. An unsuppressed water spectrum (eight averages) was also acquired and QUECC (QUALITY deconvolution and eddy current correction) was applied to correct for lineshape distortion (Bartha et al., 2000). Metabolite spectra were fitted using fitMAN software incorporated into a graphical user interface written in the IDL (Inter- active Data Language) programming language (Kassem and Bartha, 2003).

In vivo microdialysis and interstitial fluid lactate measurements. The interstitial fluid (ISF) of the hippocampus was sampled using in vivo microdialysis at a flow rate of $1 \mu \mathrm{l} / \mathrm{min}$. Hippocampal ISF was sampled hourly for $6-8 \mathrm{~h}$ and ISF lactate concentrations were quantified on a YSI 2900 analyzer (YSI) as previously described (Macauley et al., 2015).

Western blot analysis and of brain extracts. Following perfusion with Dulbecco's PBS (DPBS), pH 7.4, the brains of mice were removed and the frontal cortex of the right hemisphere was homogenized in an extraction buffer containing $50 \mathrm{~mm}$ Tris, $\mathrm{pH}$ 7.5, 2\% SDS, and protease and phosphatase inhibitors. Protein extracts were resolved by $10 \%$ SDS-PAGE, and electroblotted onto a PVDF membrane (Bio-Rad). Membranes were probed with the following antibodies: pyruvate dehydrogenase kinase (PDK1; Enzo Life Sciences), pyruvate dehydrogenase-E1 $\alpha$ (PDH-E1 $\alpha$; $\mathrm{pSer}^{232}$; Calbiochem), PDH-E1 $\alpha$ (Abcam), lactate dehydrogenase B (LDHB; Abcam), monocarboxylate transporter isoform 2 (MCT2), monocarboxylate transporter isoform 4 (MCT4; Millipore), lactate dehydrogenase A (LDHA), pyruvate kinase-M2 isoform (PKM2), pyruvate kinase-M1 isoform (PKM1), and $\beta$-actin (Cell Signaling Technology). Incubation followed with an appropriate horseradish peroxidaseconjugated secondary antibody (Bio-Rad). The blots were developed using Pierce ECL Western blotting substrate (ThermoFisher Scientific) and visualized with a Bio-Rad Molecular Imager (ChemiDoc XRS, BioRad). Densitometric analysis was performed using Quantity One software (Bio-Rad).

Preparation of mouse brain soluble and insoluble $A \beta$ extracts and ELISAs. Mouse brain tissue from the frontal cortex was extracted as described above, sonicated briefly, and centrifuged at $100,000 \times g$ for $1 \mathrm{~h}$ at $4^{\circ} \mathrm{C}$. The supernatant was collected as the soluble $\mathrm{A} \beta$ fraction and initially diluted in cold reaction buffer (DPBS containing 5\% BSA and $0.03 \%$ Tween 20 ). For the insoluble $A \beta$ fraction, the pellet was dissolved in $70 \%$ formic acid and sonicated briefly before centrifugation at $100,000 \times g$ for $1 \mathrm{~h}$ at $4^{\circ} \mathrm{C}$. ELISAs for $\mathrm{A} \beta 40$ and $\mathrm{A} \beta 42$ (Life Technologies) were performed according to the manufacturer's instructions.

Immunohistochemistry and confocal microscopy. Left hemibrains were fixed in $4 \%$ paraformaldehyde at $4^{\circ} \mathrm{C}$ overnight, then incubated in $30 \%$ sucrose at $4^{\circ} \mathrm{C}$ for $48 \mathrm{~h}$, and snap frozen in O.C.T. compound (TissueTek). Brain tissues were sectioned on a serial sagittal plane at $30 \mu \mathrm{m}$ and free-floating brain slices were washed in PBS, permeabilized using PBST (PBS and $0.1 \%$ Triton $\mathrm{X}-100$ ), and then blocked overnight at $4^{\circ} \mathrm{C}$ in $10 \%$ goat serum in PBST. Sections were incubated in the following primary antibody solutions in PBS overnight at $4^{\circ} \mathrm{C}$ : PDK1 (Enzo Life Sciences), LDHA (Cell Signaling Technology), GFAP (Abcam), and TUJ1 (Abcam). Sections were washed in PBS and incubated in secondary antibodies Alexa Fluor 488 and Alexa Fluor 647 (Life Technologies) for $1 \mathrm{~h}$ at room temperature. For staining of $A \beta$ plaques, sections were dehydrated with $80 \%$ ethanol and then incubated in $0.01 \%$ thioflavin S (Sigma-Aldrich) for $15 \mathrm{~min}$ at room temperature, followed by rehydration in PBS and mounting with ProLong Gold antifade reagent (Life Technologies) on slides.

Statistical analysis. Two-way ANOVA and Tukey's post hoc comparisons were used to analyze the difference between the genotypes over the course of aging for lactate levels deduced by ${ }^{1} \mathrm{H}$-MRS analysis and the genotypes at different ages for band intensity derived from Western blot band densitometry. For in vivo microdialysis of ISF lactate levels, a oneway or two-way ANOVA and post hoc tests were performed. A two-factor linear regression model was used to analyze the difference between genotypes for correlation of memory performance in the MWM and relative band intensity by Western blot. Statistical evaluation was performed using RStudio v0.97.551.

\section{Results}

Lactate levels in the frontal cortex decline with age in control mice but are maintained in APP/PS1 mice

To examine changes to brain lactate levels over the course of normal aging, in vivo ${ }^{1} \mathrm{H}$-MRS was performed on the frontal cortex of control and APP/PS1 mice (Fig. 1A). Lactate was identified as a peak at $1.33 \mathrm{ppm}($ Fig. $1 B)$ and quantified as a ratio to 
A

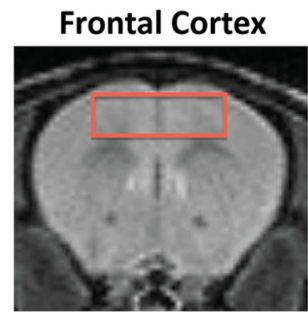

B
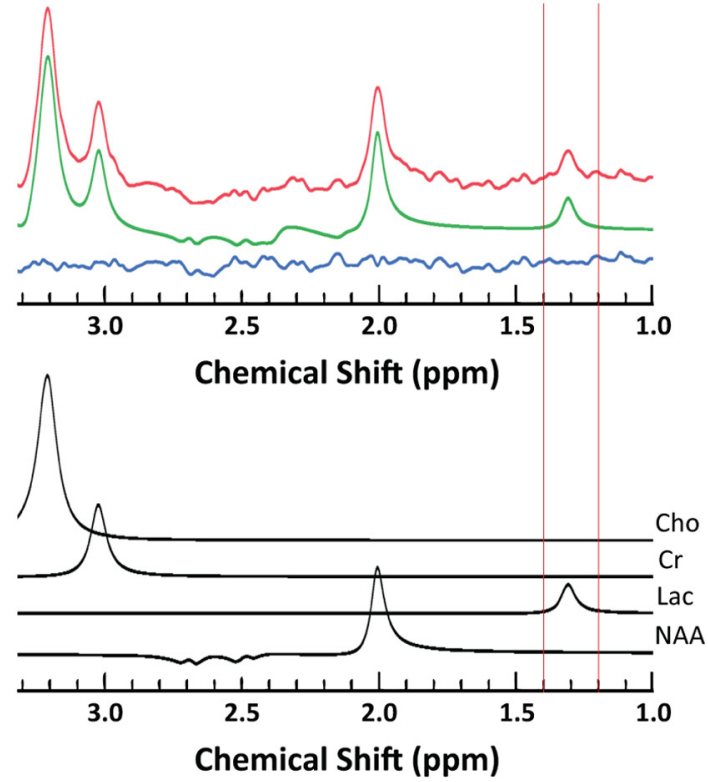

C

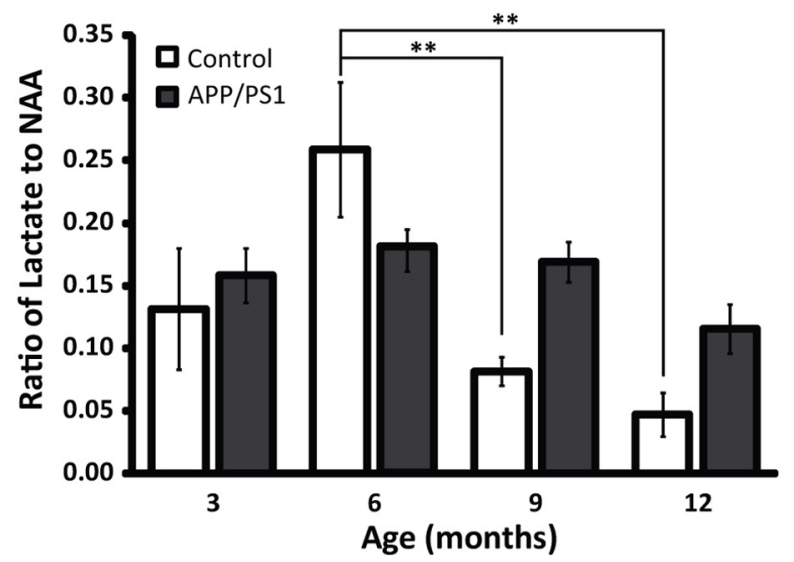

D

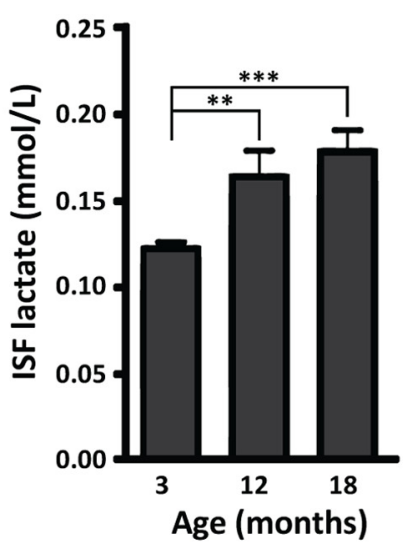

E

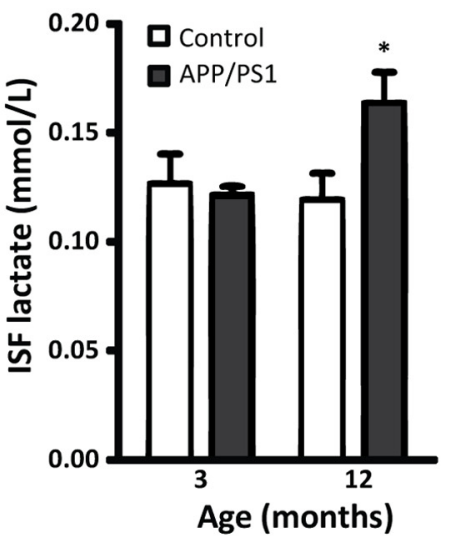

Figure 1. Lactate levels are elevated in the cortex and hippocampus of aged APP/PS1 mice. $\boldsymbol{A}$, Volume of interest in frontal cerebral cortex in the coronal plane. $\boldsymbol{B}$, Representative spectrum showing the raw data (red line) obtained from the cortex of a 6-month-old APP/PS1 mouse, the fitted result (green line), and the residual line (blue line), which is the difference between the fit and the spectrum. Cho, Choline; $C r$, creatine; Lac, lactate (highlighted by vertical red lines between 1.2 and 1.4 ppm); NAA, N-acetylaspartate. C, Quantification of average lactate as a ratio to total NAA for control mice and APP/PS1 mice ( $n=5$ and $n=12$, respectively, for ages $3-9$ months; $n=4$ and $n=3$, respectively, for age 12 months). D, Hippocampal ISF lactate levels in APP/PS1 mice are significantly elevated at 12 and 18 months of age compared with 3-month-old mice. $\boldsymbol{E}$, A significant difference in hippocampal ISF lactate levels between control and APP/PS1 mice was detected at 12 months of age. ${ }^{*} p<0.05,{ }^{* *} p<0.01,{ }^{* * *} p<0.001$. Data are shown as mean \pm SEM.

the standard metabolite $N$-acetylaspartate. Lactate was measured at 3, 6, 9, and 12 months of age (Fig. 1C) and a two-way ANOVA (age $\times$ genotype) followed by a Tukey's post hoc comparison test was performed. This analysis revealed a significant effect of age $\left(F_{(3,44)}=5.105, p=0.004\right)$ and interaction between age and genotype $\left(F_{(3,44)}=3.288, p=0.029\right)$. Cortical lactate levels were observed to progressively decline starting at 9 months of age $(p=$ 0.008 ). In contrast, cortical lactate levels did not significantly change for APP/PS1 mice throughout the course of aging. To rule out the possibility that the anesthetic isoflurane might influence brain metabolism during MRS analysis, in vivo microdialysis was performed in awake, freely moving mice to assess lactate levels in the hippocampal ISF (Fig. 1D,E). A one-way ANOVA followed by a Tukey's post hoc test revealed a significant age-dependent rise in lactate levels in APP/PS1 mice from 3 to 18 months of age $\left(F_{(2,84)}=20.53,{ }^{* *} p<0.01,{ }^{* *} p<0.001\right)$. Furthermore, hippocampal ISF lactate levels were significantly elevated in APP/PS1 mice at 12 months of age compared with control mice using a two-way ANOVA followed by a Bonferroni's post hoc test $\left(F_{(1,75)}=5.870,{ }^{\star} p<0.05\right)$. These observations reveal an agedependent elevation in lactate levels within the cortex and hippocampus of APP/PS1 mice compared with control mice.

Age-dependent decline in aerobic glycolysis enzyme expression in the frontal cortex

To explore the mechanism by which lactate levels change in the brain with age, we next examined the expression of proteins re- sponsible for lactate production, consumption, or transport (Fig. $2 A$ ) within the frontal cortex of control and APP/PS1 mice at 6 and 12 months of age by Western blot analysis (Fig. 2B). A twoway ANOVA (age $\times$ genotype) analysis of band intensity (Fig. $2 C$ ) revealed a significant age-dependent decline for markers of aerobic glycolysis, including the following: $\operatorname{PDK} 1\left(F_{(1,12)}=\right.$ 39.677, $p<0.001)$, PDH-p/PDH $\left(F_{(1,12)}=9.006, p=0.011\right)$, LDHA $\left(F_{(1,12)}=24.008, p<0.001\right), \operatorname{LDHB}\left(F_{(1,12)}=4.720, p=\right.$ $0.050), \operatorname{PKM} 2\left(F_{(1,12)}=7.168, p=0.020\right)$, and PKM1 $\left(F_{(1,12)}=\right.$ $22.118, p<0.001)$. In contrast, lactate transporter expression was elevated with age in control mice $\left(\mathrm{MCT} 2: F_{(1,12)}=5.590, p=\right.$ $0.036^{\star}$; MCT4: $\left.F_{(1,12)}=38.685, p<0.001^{\star * *}\right)$. These observations collectively suggest an age-dependent decline in aerobic glycolysis in the frontal cortex of both control mice and APP/PS1 mice, yet a compensatory increase in lactate transporter expression may occur in control mice.

Inverse relationship between aerobic glycolysis enzyme expression and memory performance in APP/PS1 mice

To determine whether aerobic glycolysis in the frontal cortex affects memory, the expression of aerobic glycolysis enzymes was compared with individual performances in the MWM at 12 months of age (Fig. 3A). A multiple linear regression model (relative band intensity $X$ genotype) was then performed on the percentage of time spent in the correct quadrant during the probe trial. This analysis revealed a significant interaction for enzymes involved in lactate production (LDHA: $R^{2}=0.740, p=0.008$; 
A

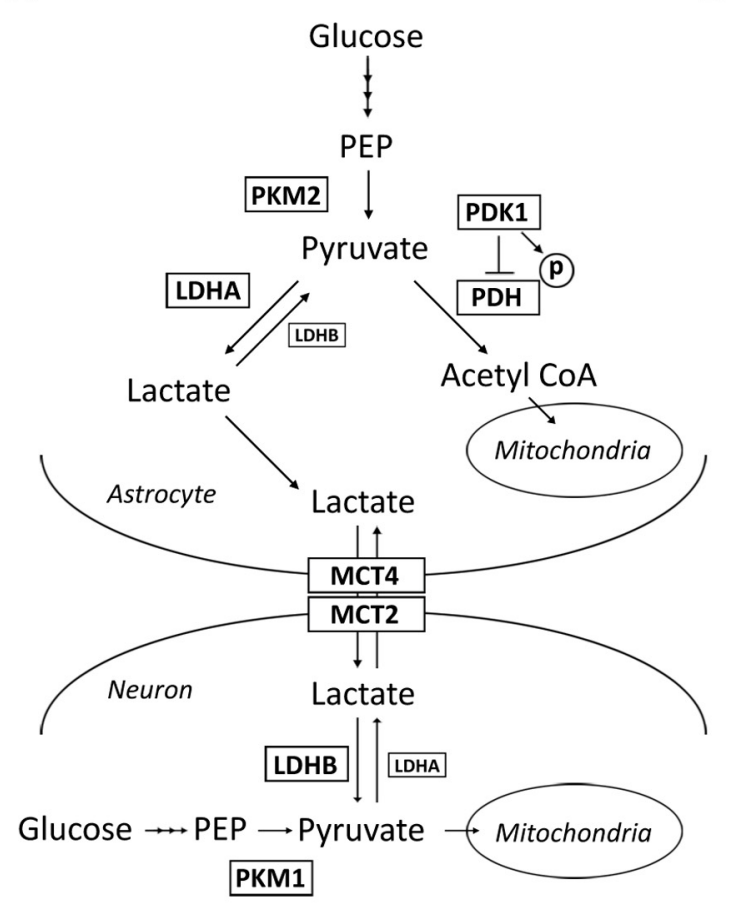

B

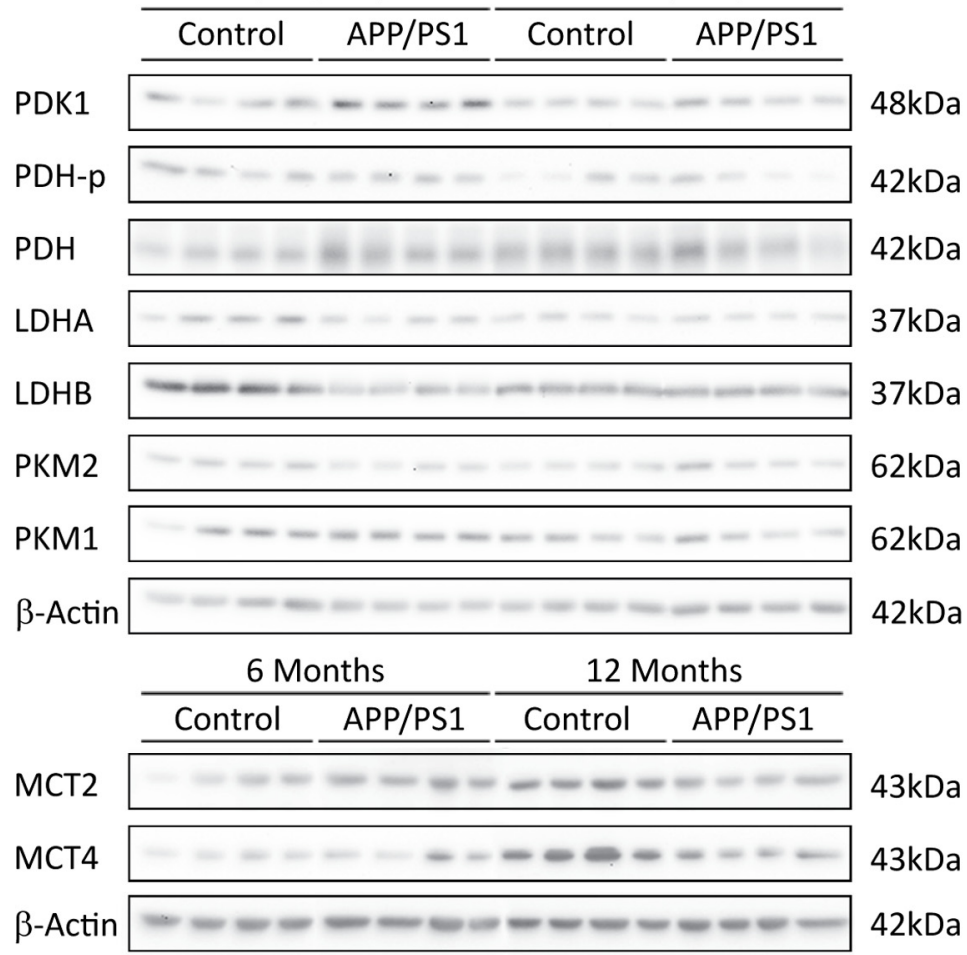

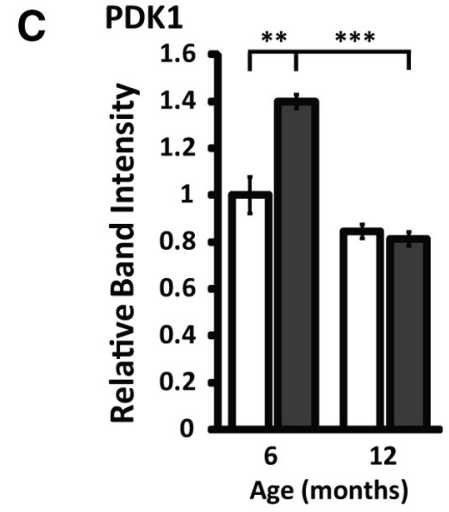

PKM2

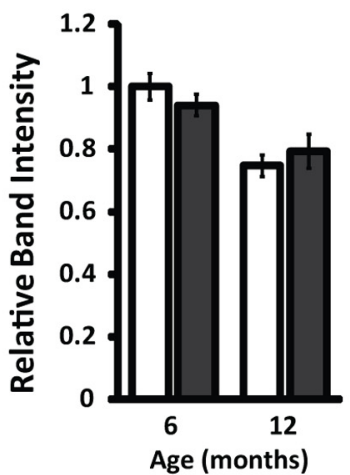

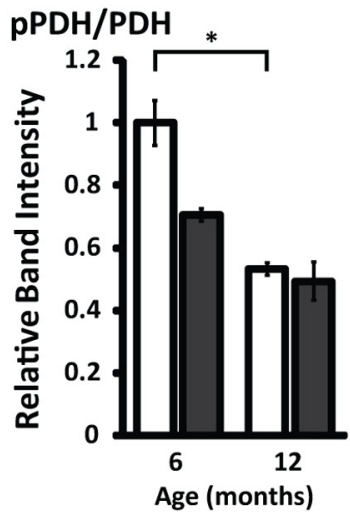

PKM1

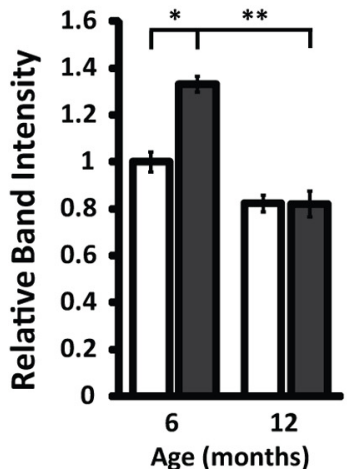

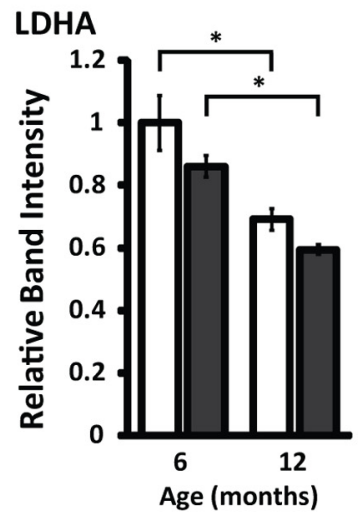

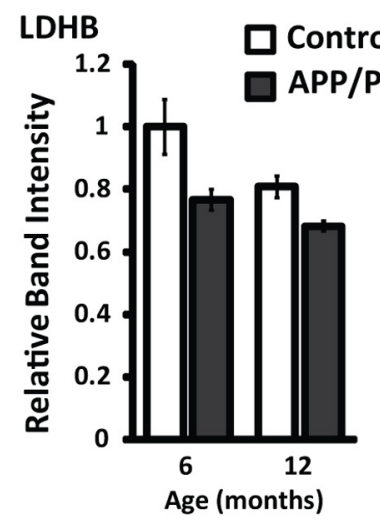

MCT2

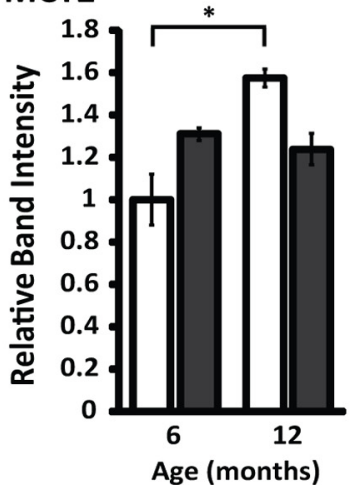

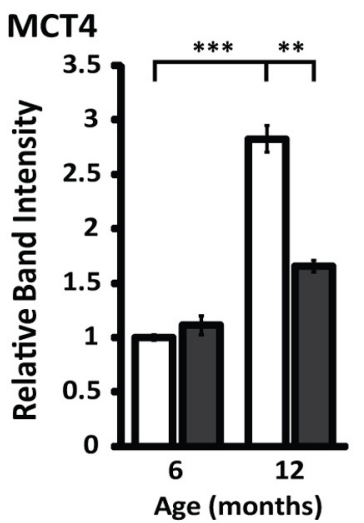

Figure 2. Age-dependent decline in expression of aerobic glycolysis proteins in the frontal cortex. $A$, Metabolic pathway of enzymes involved in aerobic glycolysis and lactate production includes pyruvate dehydrogenase kinase 1 (PDK1), lactate dehydrogenase A (LDHA), and pyruvate kinase M2 (PKM2). Enzymes that favor oxidative phosphorylation include lactate dehydrogenase B (LDHB), pyruvate kinase M1 (PKM1), and pyruvate dehydrogenase (PDH). Moncarboxylate transporter 4 (MCT4) and monocarboxylate transporter 2 (MCT2) are involved in shuttling lactate between astrocytes and neurons, respectively. $\boldsymbol{B}$. Western blot analysis of mouse cortical extracts from 6-month-old and 12-month-old control mice and APP/PS1 mice using the indicated antibodies. $\boldsymbol{C}$, Quantification of band densitometry of Western blots for markers of aerobic glycolysis and lactate production relative to $\beta$-actin shown as a ratio to 6 months control levels. ${ }^{*} p<0.05$, ${ }^{* *} p<0.01$, ${ }^{* * *} p<0.001$. Data are shown as mean \pm SEM. 
A
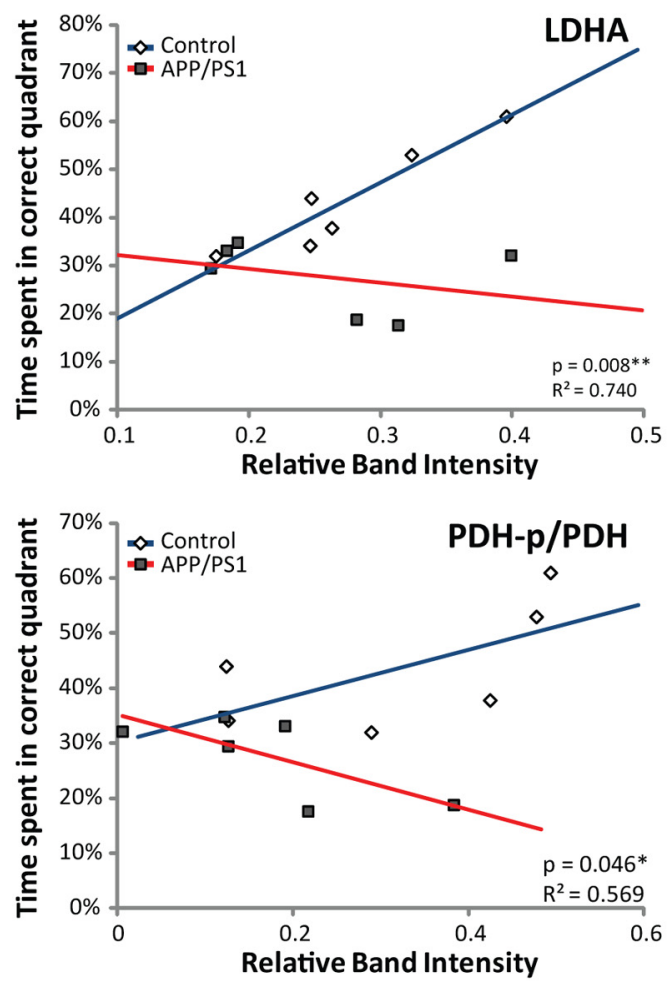

B
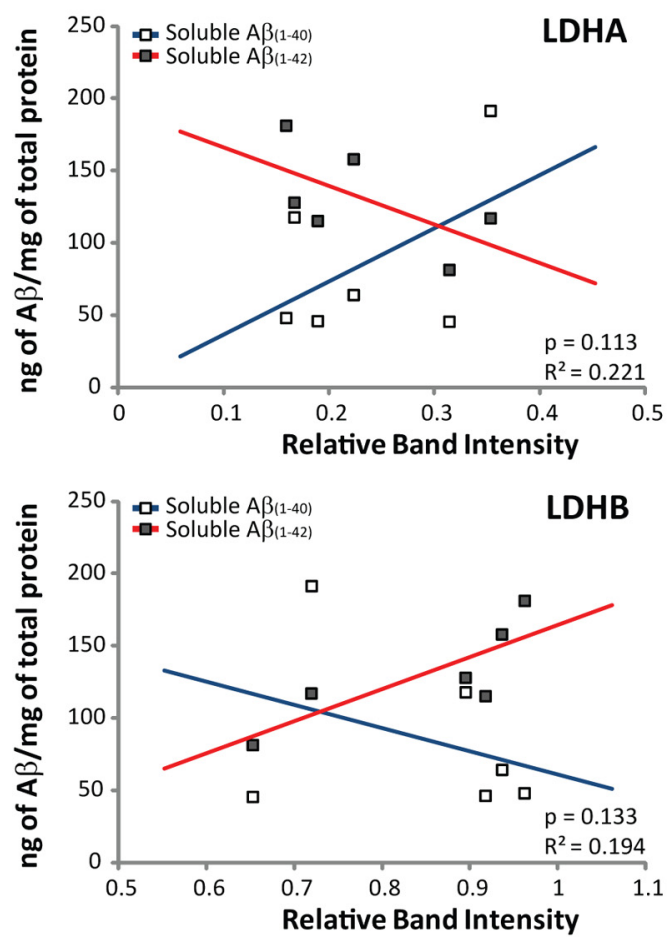
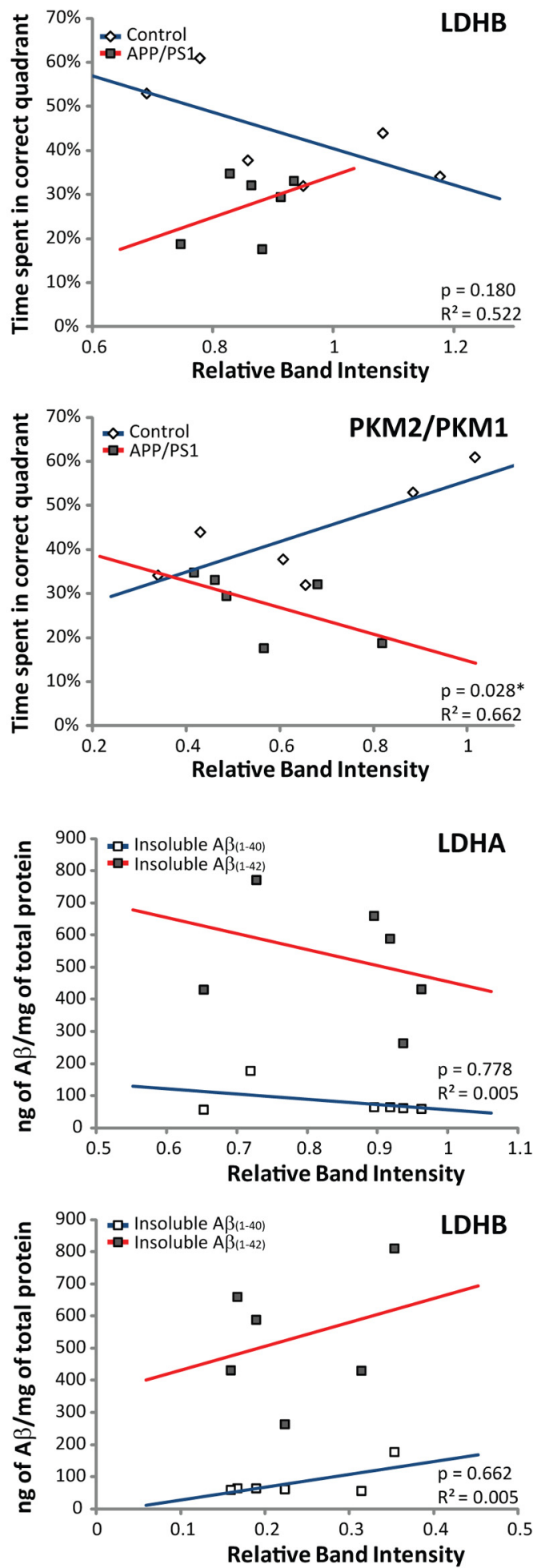

Figure 3. Inverse relationship between aerobic glycolysis enzyme expression and memory performance in APP/PS1 mice. $A$, Memory performance in the MWM correlated with the expression of aerobic glycolysis enzymes in the frontal cortex of both control mice $(n=6)$ and APP/PS1 mice $(n=6)$ at 12 months of age. Higher expression of enzymes involved in lactate production, including lactate dehydrogenase A (LDHA), pyruvate kinase M2/M1 ratio (PKM2/PKM1) and phospho-pyruvate dehydrogenase versus total pyruvate dehydrogenase (PDK-p/PDH) correlated with better memory performance for control mice, but not for APP/PS1 mice. Higher expression of lactate dehydrogenase B (LDHB), an enzyme that consumes lactate, correlated with decreased memory performance for control mice, but an increase in memory performance for APP/PS1 mice. $B$, Levels of $A \beta_{(1-40)} / A \beta_{(1-42)}$ in both soluble (left) and insoluble (right) cortical extracts from APP/PS1 mice at 12 months of age were correlated with LDHA and LDHB expression. An inverse trend between $A \beta_{1-42}$ levels and LDHA was detected. Increased levels of $A \beta_{(1-42)}$ weakly correlated with elevated expression of LDHB. ${ }^{*} p<0.05$, ${ }^{* *} p<0.01$.

PKM2/PKM1: $R^{2}=0.662, p=0.028 ;$ PDH-p/PDH: $R^{2}=0.569$, $p=0.046)$, suggesting that higher expression of these proteins correlates with better memory performance in control mice and worse performance in APP/PS1 mice. Interestingly, an inverse relationship was observed for LDHB, an enzyme that consumes lactate. Higher LDHB expression correlated with a decline in memory performance in control mice, yet showed a trend toward improved memory performance in APP/PS1 mice $\left(R^{2}=0.522\right.$, 
$p=0.180)$. To examine the relationship between $\mathrm{A} \beta$ load and enzyme expression, ELISA analysis of $A \beta$ levels in APP/PS1 mice at 12 months of age was performed (Fig. $3 B$ ). Increased levels of $\mathrm{A} \beta_{(1-42)}$ weakly correlated with decreased expression of LDHA $\left(R^{2}=0.221, p=0.113\right)$, whereas a positive correlation was noted for LDHB expression $\left(R^{2}=0.194, p=\right.$ $0.133)$. No significant association or trend was observed between $A \beta$ levels and expression of other enzymes involved in aerobic glycolysis (data not shown). Altogether these data suggest that lactate production in the frontal cortex may contribute to improved memory processing in control mice, yet may in fact be detrimental to APP/PS1 mice. In addition, elevated levels of $\mathrm{A} \beta_{(1-42)}$, but not $\mathrm{A} \beta_{(1-40)}$, may promote increased consumption rather than production of lactate in APP/ PS1 mice.

\section{PDK1 and LDHA are expressed in both} astrocytes and neurons

To our knowledge, the spatial expression of enzymes responsible for aerobic glycolysis and lactate production in the mouse brain with age has not been examined. To identify which cell types are expressing the enzymes responsible for aerobic glycolysis and lactate production, frozen brain sections from control and APP/PS1 mice at 12 months old were immunostained using antibodies specific for PDK1 and LDHA and costained with antibodies for astrocytes (GFAP) and neurons (TUJ1). Within the frontal cortex of control mice, PDK1 and LDHA expression was localized primarily to the soma of TUJ1+ neurons (Fig. 4A). Interestingly, in the frontal cortex of APP/ PS1 mice, PDK1 and LDHA were primarily expressed in the soma of TUJ1+ neurons, yet were also expressed in GFAP+ reactive astrocytes surrounding amyloid plaques (Fig. 4B). These observations indicate that PDK1 and LDHA are expressed primarily in the cell bodies of neurons, yet both cell types may be capable of producing lactate through aerobic glycolysis.

\section{Discussion}

This study revealed that age-dependent alterations in lactate metabolism are strongly associated with memory in both control and transgenic AD mice but in opposite ways. Metabolic coupling of astrocytes and neurons in the brain has been examined extensively, yet little emphasis has been placed on examining changes in this metabolism with age. In this study, ${ }^{1} \mathrm{H}-\mathrm{MRS}$ analysis of the frontal cortex re-
A
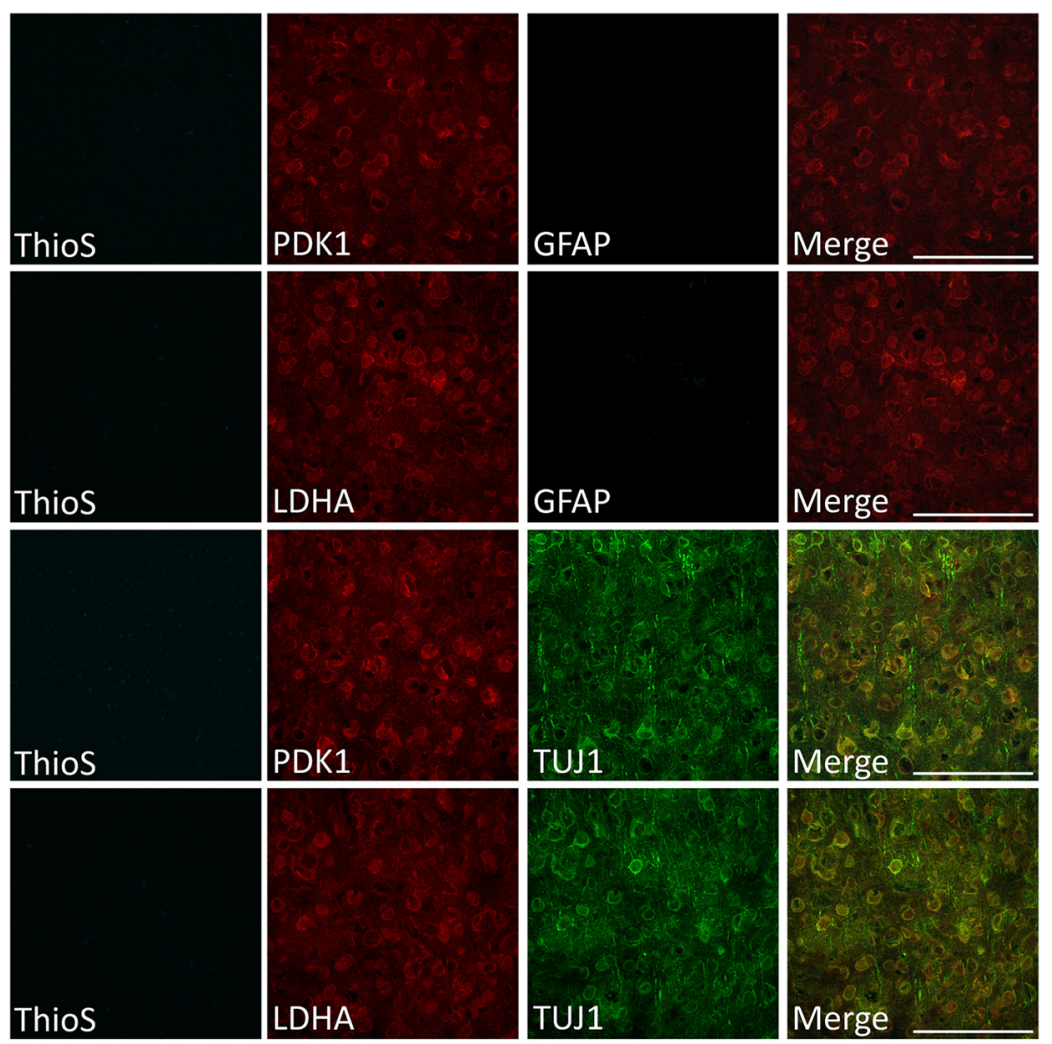

B
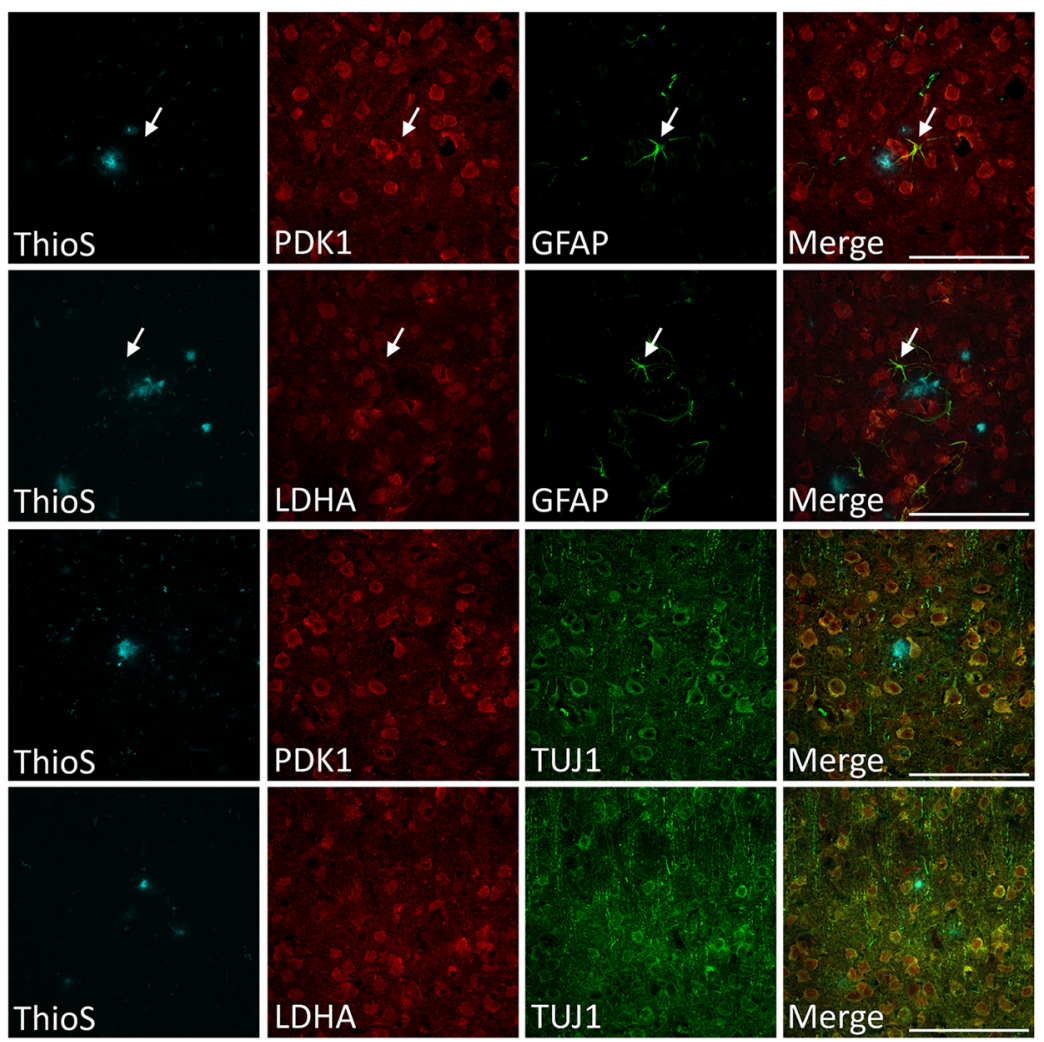

Figure 4. PDK1 and LDHA expression is primarily restricted to the soma of neuron-specific class III beta-tubulin positive $(\mathrm{TUJ1}+)$ neurons in the frontal cortex and also glial fibrillary acidic protein positive $($ GFAP + ) reactive astrocytes surrounding plaques in APP/PS1 mice. $\boldsymbol{A}, \boldsymbol{B}$, Fluorescence micrographs of the frontal cortex in control mice $(\boldsymbol{A})$ and APP/PS1 mice $(\boldsymbol{B})$ at 12 months of age. Thioflavin $S$ was used to visualize amyloid plaque deposits (blue) while immunofluorescence was used to colocalize expression of PDK1 (red) and LDHA (red) with markers for astrocytes (GFAP +, green) and neurons (TUJ1+, red). Merged images indicate that PDK1 and LDHA are expressed primarily in the soma of TUJ1+ neurons. White arrows indicate colocalized expression of PDK1 and LDHA in cortical GFAP + cells in APP/PS1 mice. Scale bar, $100 \mu \mathrm{m}$. 
vealed a decline in lactate levels with age for control mice, whereas lactate levels remained elevated in older APP/PS1 mice. Furthermore, hippocampal ISF lactate levels were elevated in APP/PS1 mice relative to control mice at 12 months of age, a time point when cognitive deficits occur in transgenic mice. In support of our findings, a recent ${ }^{1} \mathrm{H}$-MRS longitudinal study of metabolites in healthy C57BL/6 mice between 3 and 24 months of age also revealed a progressive decline in lactate levels in the cortex but not hippocampus (Duarte et al., 2014). In contrast, an earlier study using ${ }^{1} \mathrm{H}$-MRS reported that cortical lactate levels increase with age in a mitochondrial DNA mutator mouse model of advanced aging, an event associated with an increase in the ratio of LDHA to LDHB (Ross et al., 2010).

Few ${ }^{1} \mathrm{H}$-MRS studies measuring lactate in the aging human brain have been conducted. In one report, lactate levels increased in the left frontal lobe of young subjects (19-24 years old), but not in healthy aged subjects (60-68 years old), engaged in a silent word-generation task (Urrila et al., 2004). Elevated lactate levels within the precuneus/posterior cingulate of individuals with mild cognitive impairment were recently found to negatively correlate with memory performance (Weaver et al., 2015). In addition, AD patients show a significant increase in CSF lactate levels compared with age-matched nondemented individuals or patients with vascular dementia (Liguori et al., 2015). Finally, intravenous lactate infusion does not improve semantic memory in $\mathrm{AD}$ patients (Kálmán et al., 2005). Collectively, these observations suggest that elevated cerebral lactate may actually interfere with memory processes in AD.

The mechanism by which $\mathrm{A} \beta$ alters glycolytic metabolism is poorly defined. An $\mathrm{A} \beta$-stimulated increase in glucose uptake in the cortex and hippocampus has previously been reported in 12-month-old APP/PS1 mice (Poisnel et al., 2012). Moreover, induction of acute hyperglycemia resulted in increased hippocampal ISF lactate levels and neuronal activity in APP/PS1 mice (Macauley et al., 2015). Our observation of elevated lactate levels in the frontal cortex and hippocampus of APP/PS1 mice at 12 months of age compared with controls may be explained by enhanced glucose uptake and neuronal activity. It is also possible that lactate transport is compromised in the aging brain or is negatively affected by $\mathrm{A} \beta$ deposition. Unexpectedly, we observed an inverse correlation between $\mathrm{A} \beta_{(1-40)}$ and $\mathrm{A} \beta_{(1-42)}$ levels with LDHA and LDHB expression in the cortex. Further investigation is warranted to determine the exact changes in lactate metabolism that occur as a consequence of the aging process and in an $\mathrm{AD}$ context.

Lactate production and transport between astrocytes and neurons are required for learning and long-term memory formation (Newman et al., 2011; Suzuki et al., 2011). Our results indicate that control mice with higher expression of lactate-producing enzymes in the frontal cortex have improved memory. These observations suggest that lactate production in the frontal cortex is a key determinant of memory function and implicate aerobic glycolysis as a mechanism to supply fuel to active regions of the brain (Vlassenko et al., 2006). Lactate has been shown to potentiate NMDA receptor-mediated signaling by modulating the redox state in neurons and also by inducing expression of genes associated with synaptic plasticity (Barros, 2013; Yang et al., 2014).

Paradoxically, we observed a decline in memory performance in APP/PS1 mice that correlated with increased expression of lactate-producing enzymes and elevated ISF hippocampal lactate levels. Multimodal PET imaging measuring A $\beta$ deposition, glucose consumption, and oxygen utilization revealed a strong cor- relation between the spatial distribution of elevated aerobic glycolysis and $\mathrm{A} \beta$ deposition in brain tissue (Vlassenko et al., 2010). We previously demonstrated that nerve cells selected for resistance to $\mathrm{A} \beta$ toxicity upregulate aerobic glycolysis as a protective mechanism (Newington et al., 2012). It is possible that elevated aerobic glycolysis occurs during the prodromal phase of $\mathrm{AD}$ as a compensatory mechanism to mitigate the toxic effects of $\mathrm{A} \beta$ accumulation and maximize energy utilization. However, during progression of the disease, aerobic glycolysis and lactate production may in fact be detrimental and contribute to the cognitive decline associated with $\mathrm{AD}$.

In this study, we observed that PDK1 and LDHA (both markers of aerobic glycolysis) are expressed primarily in the soma of neurons in the frontal cortex of control mice and of both neurons and astrocytes surrounding plaques in the frontal cortex of APP/ PS1 mice. This observation suggests that neurons are capable of generating lactate, although the purpose of neuron-derived lactate remains unclear. It has recently been suggested that lactate, not pyruvate, is the primary end product of glycolysis in fully oxygenated cells, including neurons (Rogatzki et al., 2015). Lactate may be produced as a metabolic intermediate in the cytosol that is shuttled into the mitochondria to be oxidized as a fuel source (Stainsby and Brooks, 1990). Interestingly, genetic manipulation of metabolism to promote increased lactate production results in oxidative stress and apoptosis within rat cortical neurons but not in astrocytes (Herrero-Mendez et al., 2009). It is possible that elevated intracellular lactate promotes neuronal death in $\mathrm{AD}$. Further investigation is warranted to elucidate the exact role of lactate production, consumption, or transport in astrocytes and neurons to identify key molecular targets for therapeutic treatment of $\mathrm{AD}$.

\section{References}

Atamna H, Frey WH 2nd (2007) Mechanisms of mitochondrial dysfunction and energy deficiency in Alzheimer's disease. Mitochondrion 7:297-310. CrossRef Medline

Barros LF (2013) Metabolic signaling by lactate in the brain. Trends Neurosci 36:396-404. CrossRef Medline

Bartha R, Drost DJ, Menon RS, Williamson PC (2000) Spectroscopic lineshape correction by QUECC: combined QUALITY deconvolution and eddy current correction. Magn Reson Med 44:641-645. CrossRef Medline

Duarte JM, Do KQ, Gruetter R (2014) Longitudinal neurochemical modifications in the aging mouse brain measured in vivo by $1 \mathrm{H}$ magnetic resonance spectroscopy. Neurobiol Aging 35:1660-1668. CrossRef Medline

Fox PT, Raichle ME, Mintun MA, Dence C (1988) Nonoxidative glucose consumption during focal physiologic neural activity. Science 241:462464. CrossRef Medline

Herrero-Mendez A, Almeida A, Fernández E, Maestre C, Moncada S, Bolaños JP (2009) The bioenergetic and antioxidant status of neurons is controlled by continuous degradation of a key glycolytic enzyme by APC/CCdh1. Nat Cell Biol 11:747-752. CrossRef Medline

Jankowsky JL, Slunt HH, Ratovitski T, Jenkins NA, Copeland NG, Borchelt DR (2001) Co-expression of multiple transgenes in mouse CNS: a comparison of strategies. Biomol Eng 17:157-165. CrossRef Medline

Kálmán J, Palotás A, Kis G, Boda K, Túri P, Bari F, Domoki F,Dóda I, Argyelán M, Vincze G, Séra T, Csernay L, Janka Z, PávicsL (2005) Regional cortical blood flow changes following sodium lactate infusion in Alzheimer's disease. Eur J Neurosci 21:1671-1678. CrossRef Medline

Kassem MN, Bartha R (2003) Quantitative proton short-echo-time LASER spectroscopy of normal human white matter and hippocampus at 4 Tesla incorporating macromolecule subtraction. Magn Reson Med 49:918927. CrossRef Medline

Liguori C, Stefani A, Sancesario G, Sancesario GM, Marciani MG, Pierantozzi M (2015) CSF lactate levels, $\tau$ proteins, cognitive decline: a dynamic relationship in Alzheimer's disease. J Neurol Neurosurg Psychiatry 86: 655-659. CrossRef Medline

Lunt SY, Vander Heiden MG (2011) Aerobic glycolysis: meeting the meta- 
bolic requirements of cell proliferation. Annu Rev Cell Dev Biol 27:441464. CrossRef Medline

Macauley SL, Stanley M, Caesar EE, Yamada SA, Raichle ME, Perez R, Mahan TE, Sutphen CL, Holtzman DM (2015) Hyperglycemia modulates extracellular amyloid- $\beta$ concentrations and neuronal activity in vivo. J Clin Invest 125:2463-2467. CrossRef Medline

Magistretti PJ, Allaman I (2015) A cellular perspective on brain energy metabolism and functional imaging. Neuron 86:883-901. CrossRef Medline

Morris R (1984) Developments of a water-maze procedure for studying spatial learning in the rat. J Neurosci Methods 11:47-60. CrossRef Medline

Mosconi L, Sorbi S, de Leon MJ, Li Y, Nacmias B, Myoung PS, Tsui W, Ginestroni A, Bessi V, Fayyazz M, Caffarra P, Pupi A (2006) Hypometabolism exceeds atrophy in presymptomatic early-onset familial Alzheimer's disease. J Nucl Med 47:1778-1786. Medline

Mosienko V, Teschemacher AG, Kasparov S (2015) Is L-lactate a novel signaling molecule in the brain? J Cereb Blood Flow Metab 35:1069-1075. CrossRef Medline

Newington JT, Rappon T, Albers S, Wong DY, Rylett RJ, Cumming RC (2012) Overexpression of PDK1 and LDHA in nerve cells confers resistance to amyloid beta and other toxins by decreasing mitochondrial respiration and ROS production. J Biol Chem 287:37245-37258. CrossRef Medline

Newman LA, Korol DL, Gold PE (2011) Lactate produced by glycogenolysis in astrocytes regulates memory processing. PLoS One 6:e28427. CrossRef Medline

Poisnel G, Hérard AS, El Tannir El Tayara N, Bourrin E, Volk A, Kober F, Delatour B, Delzescaux T, Debeir T, Rooney T, Benavides J, Hantraye P, Dhenain M (2012) Increased regional cerebral glucose uptake in an APP/PS1 model of Alzheimer's disease. Neurobiol Aging 33:1995-2005. CrossRef Medline

Rogatzki MJ, Ferguson BS, Goodwin ML, Gladden LB (2015) Lactate is al- ways the end product of glycolysis. Front Neurosci 9:22. CrossRef Medline

Ross JM, Öberg J, Brené S, Coppotelli G, Terzioglu M, Pernold K, Goiny M, Sitnikov R, Kehr J, Trifunovic A, Larsson NG, Hoffer BJ, Olson L (2010) High brain lactate is a hallmark of aging and caused by a shift in the lactate dehydrogenase A/B ratio. Proc Natl Acad Sci U S A 107:20087-20092. CrossRef Medline

Stainsby WN, Brooks GA (1990) Control of lactic acid metabolism in contracting muscles and during exercise. Exerc Sport Sci Rev 18:29-63. Medline

Suzuki A, Stern SA, Bozdagi O, Huntley GW, Walker RH, Magistretti PJ, Alberini CM (2011) Astrocyte-neuron lactate transport is required for long-term memory formation. Cell 144:810-823. CrossRef Medline

Urrila AS, Hakkarainen A, Heikkinen S, Vuori K, Stenberg D, Häkkinen AM, Lundbom N, Porkka-Heiskanen Tzens(2004) Stimulus-induced brain lactate: effects of aging and prolonged wakefulness. J Sleep Res 13:111119. CrossRef Medline

Vlassenko AG, Rundle MM, Raichle ME, Mintun MA (2006) Regulation of blood flow in activated human brain by cytosolic NADH/NAD + ratio. Proc Natl Acad Sci U S A 103:1964-1969. CrossRef Medline

Vlassenko AG, Vaishnavi SN, Couture L, Sacco D, Shannon BJ, Mach RH, Morris JC, Raichle ME, Mintun MA (2010) Spatial correlation between brain aerobic glycolysis and amyloid- $\beta(\mathrm{A} \beta)$ deposition. Proc Natl Acad Sci U S A 107:17763-17767. CrossRef Medline

Weaver KE, Richards TL, Logsdon RG, McGough EL, Minoshima S, Aylward EH, Kleinhans NM, Grabowski TJ, McCurry SM, Teri L (2015) Posterior cingulate lactate as a metabolic biomarker in amnestic mild cognitive impairment. Biomed Res Int 2015:610605. CrossRef Medline

Yang J, Ruchti E, Petit JM, Jourdain P, Grenningloh G, Allaman I, Magistretti PJ (2014) Lactate promotes plasticity gene expression by potentiating NMDA signaling in neurons. Proc Natl Acad Sci U S A 111:12228-12233. CrossRef Medline 